Article

\title{
Swelling Behavior of Polyacrylamide-Cellulose Nanocrystal Hydrogels: Swelling Kinetics, Temperature, and pH Effects
}

\author{
Tippabattini Jayaramudu ${ }^{1,2}$, Hyun-U Ko ${ }^{1}$, Hyun Chan Kim ${ }^{1}$, Jung Woong Kim ${ }^{1}$ and \\ Jaehwan Kim 1,*(D) \\ 1 Center for Nanocellulose Future Composites, Department of Mechanical Engineering, Inha University, \\ 100 Inha-Ro, Michuhol-Gu, Incheon 22212, Korea \\ 2 Laboratory of Material Sciences, Instituto de Quimica de Recursos Naturales, Universidad de Talca, \\ Talca 747, Chile \\ * Correspondence: jaehwan@inha.ac.kr; Tel.: +82-32-831-7325
}

Received: 18 April 2019; Accepted: 26 June 2019; Published: 28 June 2019

\begin{abstract}
This paper reports swelling behavior of cellulose nanocrystal (CNC)-based polyacrylamide hydrogels prepared by a radical polymerization. The $\mathrm{CNC}$ acts as a nanofiller through the formation of complexation and intermolecular interaction. FTIR spectroscopy and XRD studies confirmed the formation of intermolecular bonds between the acrylamide and hydroxyl groups of CNC. The swelling ratio and water retention were studied in de-ionized (DI) water at room temperature, and the temperature effect on the swelling ratio was investigated. Further, the $\mathrm{pH}$ effect on the swelling ratio was studied with different temperature levels. Increasing the $\mathrm{pH}$ with temperature, the prepared hydrogel shows 6 times higher swelling ratio than the initial condition. The swelling kinetics of the developed hydrogels explains that the diffusion mechanism is Fickian diffusion mechanism. Since the developed hydrogels have good swelling behaviors with respect to $\mathrm{pH}$ and temperature, they can be used as smart materials in the field of controlled drug delivery applications.
\end{abstract}

Keywords: hydrogels; swelling; cellulose nanocrystal; diffusion; $\mathrm{pH}$-sensitive

\section{Introduction}

Hydrogels are widely utilized polymers with fascinating properties and predominantly applied in various modern scientific and technological fields [1-5]. Hydrogels have special characteristic features, that is, swelling behavior in water/biological fluids; due to this behavior, hydrogels are broadly used in many fields, including biomedical tissue engineering, drug delivery, sensors, actuators, and metal/dyes adsorption applications [6-10]. Therefore, the swelling behavior plays a significant role in hydrogel technology. The capacity of swelling behavior in hydrogels occurs as a result of ionization, which makes it possible to absorb water arising in hydrophilic functional groups attached to the cross-linked polymer backbone and through the difference in swelling osmatic pressure between the gel phase and solvent phase. Generally, hydrogels are insoluble three-dimensional hydrophilic cross-linked and tissue-like soft polymeric network structures. These network structures are achieved from a cross-linked polymer using various techniques and classified according to their synthesis techniques [5]. However, copolymerization/cross-linking free-radical polymerization techniques are most commonly used to develop hydrogels by reacting hydrophilic monomers with multifunctional cross-linkers [11]. Among the hydrophilic monomers, acrylamide/modified acrylamide is widely used in hydrogel technology due to its hydrophilic functional groups. Because of these functional groups, it is able to swell drastically in the presence of water/biological fluids without solubility. Acrylamide-based hydrogels are widely used in agriculture, tissue engineering, and biomedical and wastewater treatment $[12,13]$. To date, 
considerable studies have been done to improve the mechanical, chemical, and electromechanical properties of polyacrylamide hydrogels by blending nanofillers such as polymeric nanoparticles, inorganic clays, and metal nanoparticles [14-16]. Recently, cellulose nanocrystals (CNCs) were blended in polyacrylamide to reinforce their elastic, dielectric, and electromechanical properties, which are applicable for soft electroactive materials in an active lens [17].

Cellulose nanocrystals (CNCs) are made from acid hydrolysis of the cellulose. Cellulose is an eco-friendly organic material with low cost and high thermal stability, and it is biodegradable and biocompatible. The structure of cellulose was first demonstrated by Staudinger in 1920 through the process of acetylation and deacetylation, which also identified that anhydroglucose units are covalently bonded and able to make macromolecular chains [18]. Covalent bonds occur between the $\beta$-1,4-glycosidic bonds of the $\mathrm{C} 1$ and $\mathrm{C} 4$ of the $\beta$-D-anhydroglucopyranose monomer units and provide linear shape. The chemical stability of the cellulose is estimated based on the hydrolytic attack at the $\beta$-1,4-glycosidic linkages between the repeated units. However, cellulose consists of crystalline and amorphous domains, which are together arranged randomly, and the properties of cellulose are mainly dependent on the arrangement of these domains. The amorphous domains are removed via a simple hydrolysis reaction that can effectively deliver CNCs for many advanced industrial applications of cellulose [19-21]. In general, CNCs are rod/needle-shaped crystalline material, which is produced by concentrated sulfuric acid hydrolysis of cellulose. Normally, CNCs are less than $300 \mathrm{~nm}$ in length and $20 \mathrm{~nm}$ in width, depending on the cellulose resources [22]. Since CNC has rich hydroxyl (-OH) groups on its surface, it can be easily blended with other polymers. Owing to these properties, CNCs are broadly used in hydrogel technology to improve their physical and chemical properties for various fields, such as drug delivery, tissue engineering, and biomedical applications [23-25]. For example, CNC-reinforced gelatin hydrogels were reported for controlled drug delivery applications, using rice husks as a resource of cellulose [23]. CNC-reinforced alginate hydrogel beads were fabricated for methylene blue adsorption [26]. Recently, CNC-reinforced, mechanically stiff, and bioactive hybrid hydrogels were developed for bone tissue engineering applications [27]. CNC was incorporated into polyvinyl alcohol (PVA) to develop nontoxic and transparent electroactive hydrogels [28]. Lately, polyacrylamide (PAM)-CNC hydrogels was developed through grafting copolymerization and the shear storage modulus, compression strength, and elastic modulus of the system were studied [29]. However, in-depth analysis of its swelling kinetics and $\mathrm{pH}$ and temperature effects were not conducted.

In the present investigation, we firstly developed CNCs through acid hydrolysis of cellulose. Then, polyacrylamide-CNC (PAC) hydrogels were produced via free-radical polymerization. The PAC hydrogels developed in the presence of different concentrations of CNCs using acrylamide monomer, cross-linker, and initiators. The prepared CNC and their composite hydrogels were characterized by atomic force microscopy (AFM), Fourier transform infrared (FTIR) spectroscopy, and X-ray diffraction (XRD) studies. The thermal stability and mechanical properties were studied using thermogravimetric analysis (TGA) and compression studies. Furthermore, we studied their swelling studies in different $\mathrm{pH}$ solutions, temperatures, and combinations of $\mathrm{pH}$ and temperature effect and swelling kinetics studies.

\section{Materials and Methods}

\subsection{Materials}

Cotton pulp (MVE, DPw-4580) was supplied by Buckeye Technology Inc. (Memphis, TN, USA). Acrylamide (Am), N,N1-methylenebisacrylamide (MBA), ammonium per sulfate (APS), $\mathrm{N}, \mathrm{N}, \mathrm{N}^{\prime}, \mathrm{N}^{\prime}$-tetramethylrthylenediamine (TMEDA), and sodium hydroxide $(\mathrm{NaOH})$ were purchased from Sigma-Aldrich, Yongin, Gyeonggi-do, Korea. All chemicals were used without further purification. De-ionized (DI) water was used throughout the experimentation. 


\subsection{Preparation of CNC-PAC Hydrogels}

Firstly, CNC suspension was prepared using the acid hydrolysis technique as previously reported [30]. In a brief explanation, $10 \mathrm{~g}$ of cotton pulp was dispersed in $64 \%$ of sulfuric acid $\left(\mathrm{H}_{2} \mathrm{SO}_{4}\right)$ under constant magnetic stirring $(300 \mathrm{rpm})$ at $60{ }^{\circ} \mathrm{C}$ over a period of $2 \mathrm{~h}$. Later, the hydrolysis reaction was stopped through the addition of 10 times excess cold DI water, followed by successive centrifugation (30 min, 11,000 rpm), and finally, the suspension was dialyzed overnight to attain neutrality $\mathrm{pH}=7$. The $0.5 \mathrm{wt} \%$ of CNC suspension was prepared via re-dispersion of CNC in DI water, stored in a glass vial at $4{ }^{\circ} \mathrm{C}$ until use. Before hydrolysis, an alkaline $(1 \mathrm{M} \mathrm{NaOH})$ treatment was carried out to remove the noncellulosic components from the cotton pulp to improve the CNC quality.

The PAC hydrogels were prepared using the standard procedure reported previously $[2,10]$. In brief, $1 \mathrm{wt} \%$ of (based on Am concentration) $\mathrm{CNC}$ was dispersed in $5 \mathrm{~mL}$ of DI water under constant magnetic stirring with $200 \mathrm{rpm}$. Then, $14.08 \mathrm{mM}$ of Am was dissolved in this solution under the same stirring condition until Am was dissolved. To the solution, MBA and APS/TMEDA were added as per the specifications given in Table 1, and the mixture was stirred for another $30 \mathrm{~min}$. The solution was poured into a petri dish and kept in an oven at $45^{\circ} \mathrm{C}$, where a hydrogel was formed. The formed hydrogel was transferred into a $250 \mathrm{~mL}$ beaker containing $100 \mathrm{~mL}$ of DI water in order to remove unreacted monomers, cross-linker, and pre-polymer from the hydrogel, and the water was repeatedly changed every $6 \mathrm{~h}$ up to $48 \mathrm{~h}$ [6]. Similarly, CNC varied (1,3, and $5 \mathrm{wt}$. \%) PAC hydrogels and the pristine polyacrylamide hydrogel were synthesized using the above procedure, and the developed hydrogels were named as PAm, PAC1, PAC2m and PAC3, respectively, as shown in Table 1. Figure 1 shows the schematics of PAC hydrogel formation.
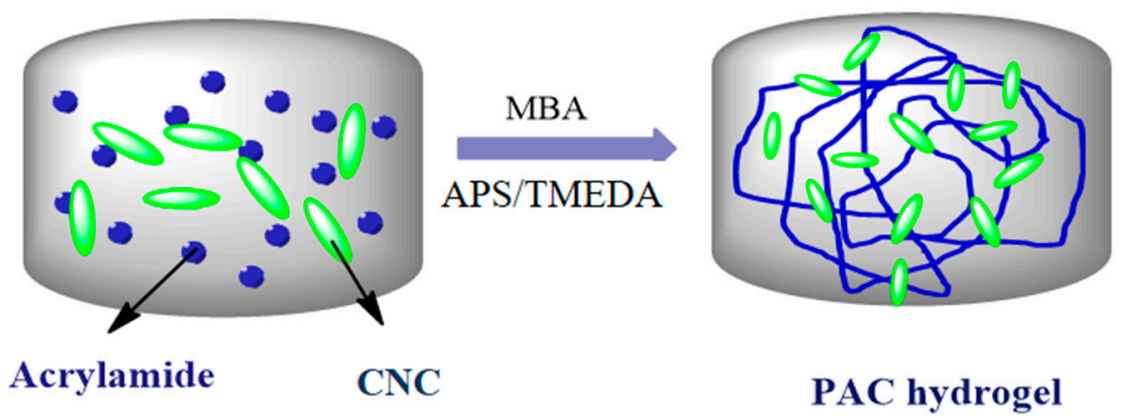

Figure 1. Schematics of polyacrylamide- cellulose nanocrystal (PAC) hydrogel formation.

Table 1. Feed composition of PAC hydrogels.

\begin{tabular}{ccccccc}
\hline $\begin{array}{c}\text { Hydrogel } \\
\text { Code }\end{array}$ & $\begin{array}{c}\text { AM } \\
(\mathbf{m M})\end{array}$ & $\begin{array}{c}\mathbf{0 . 5} \text { wt. \% CNC } \\
\mathbf{( W t . ~ \% )}\end{array}$ & $\begin{array}{c}\text { MBA } \\
\mathbf{( m M )}\end{array}$ & $\begin{array}{c}\text { APS } \\
(\mathbf{m M})\end{array}$ & $\begin{array}{c}\text { TMEDA } \\
\mathbf{( m M )}\end{array}$ & $\begin{array}{c}\text { Swelling } \\
\text { Ratio S }_{\mathbf{g} / \mathbf{g}}\end{array}$ \\
\hline PAm & 14.08 & 0 & 0.648 & 2.191 & 0.8605 & 11.69355 \\
PAC1 & 14.08 & 1 & 0.648 & 2.191 & 0.8605 & 10.8675 \\
PAC2 & 14.08 & 3 & 0.648 & 2.191 & 0.8605 & 10.3317 \\
PAC3 & 14.08 & 5 & 0.648 & 2.191 & 0.8605 & 14.1400 \\
\hline
\end{tabular}

\section{Characterization}

\subsection{Physical and Chemical Characteristics}

At first, the morphology of the prepared CNC was observed using an AFM (Dimension 3100, Veeco, San Jose, CA, USA) in the tapping mode. The CNC specimen was made by vacuum spraying the prepared CNC on a cleaned silicon wafer. To study the formation of the PAC hydrogels, FTIR spectra were taken. The FTIR samples were prepared by completely drying the prepared hydrogels in the oven at $60^{\circ} \mathrm{C}$ for $6 \mathrm{~h}$. The samples were examined on an FTIR spectrometer (Veratex-80, Bruker Optics, Billerica, MA, USA) using the $\mathrm{KBr}$ pellet method between $400-4000 \mathrm{~cm}^{-1}$. The thermal behavior of 
the prepared hydrogels was studied via thermogravimetric analysis (TGA) and differential thermal analysis (DTA) (STA $409 \mathrm{PC}$, Selb, Germany), at a heating rate of $10^{\circ} \mathrm{C} / \mathrm{min}$ under a constant nitrogen flow $(20 \mathrm{~mL} / \mathrm{min})$. Wide angle $\mathrm{X}$-ray diffraction was studied using $\mathrm{Cu} \mathrm{K} \alpha$ target radiation at $40 \mathrm{kV}$ and $50 \mathrm{~mA}$, at a scanning rate of $0.015^{\circ} / \mathrm{min}$. The diffraction angle was varied from $5^{\circ}$ to $45^{\circ}$. The surface and cross-section morphologies of the prepared hydrogels were studied using field emission scanning electron microscopy (FE-SEM, S-4000, Hitachi, Tokyo, Japan). The air-dried hydrogels were coated with platinum, and an accelerating voltage of $10 \mathrm{kV}$ was used during imagining.

\subsection{Swelling and Water Retention}

The swelling ratio was calculated by weighting the dried and wet hydrogels. The completely dried and pre-weighed PAm and PAC hydrogels were equilibrated in $50 \mathrm{~mL}$ of DI water in a $100 \mathrm{~mL}$ beaker, and the water-observed hydrogels were weighed after removing the surface excess water with a water-sucking filter paper at certain time intervals up to equilibrium using analytical balance (GH-200, A\&D weighing, Tokyo, Japan). Then, the equilibrated hydrogels were put in petri dishes at room temperature, and the hydrogels were re-weighted at certain time intervals until they had reached saturated weight values. The swelling ratio $\left(\mathrm{S}_{\mathrm{g} / \mathrm{g}}\right)$ and $\%$ of water retention can be calculated using the following equations:

$$
\begin{aligned}
& \text { Swelling ratio }\left(S_{g / g}\right)=\frac{W_{t}-W_{o}}{W_{o}}, \\
& \text { Water retention }(\%)=\frac{W_{t}-W_{o}}{W_{d}-W_{o}},
\end{aligned}
$$

where $W_{t}$ is the weight of the swollen hydrogel at time intervals, $W_{o}$ is the weight of dried hydrogels, and $W_{d}$ is the initial weight of the swollen hydrogel. Moreover, the swelling behavior was analyzed in different $\mathrm{pH}$ values, ranging from 2 to 12 solutions.

\section{Results and Discussion}

\subsection{PAC Hydrogel Formation}

The PAC hydrogels were prepared through free radical polymerization. Initially, rod shape and transparent CNCs were prepared via acid hydrolysis. Figure 2A shows a photograph of the transparent CNC suspension prepared in this experiment. The morphology of the prepared CNCs was confirmed by AFM, as shown in Figure 2B. CNCs have a rod-like shape with a diameter of $25-40 \mathrm{~nm}$. The transparency of the prepared CNCs is associated with their nano-size. Figure $2 \mathrm{C}$ shows the photograph of the prepared hydrogel, PAC3, which shows its transparency. Figure 3 shows a possible formation mechanism of the PAC hydrogel. The Am monomer polymerized in the presence of CNCs and formed the PAC hydrogel.

The prepared PAC hydrogels and their chemical interactions were confirmed by FTIR spectra. Figure 4 shows FTIR spectra of the CNC, Pam, and PAC hydrogels. The CNC shows a broad peak at $3366 \mathrm{~cm}^{-1}$, which are related to the $\mathrm{O}-\mathrm{H}$ stretching vibration. The $\mathrm{C}-\mathrm{H}$ stretching vibration peak is shown at $2919 \mathrm{~cm}^{-1}$. Peaks at $1663 \mathrm{~cm}^{-1}$ and $1448 \mathrm{~cm}^{-1}$ were related to the $\mathrm{O}-\mathrm{H}$ bending and $\mathrm{CH}_{2}$ scissoring motion in cellulose. Characteristics peaks were at $1390 \mathrm{~cm}^{-1}\left(\mathrm{C}-\mathrm{H}\right.$ bending), $1354 \mathrm{~cm}^{-1}$ (O-H in plane bending), $1337 \mathrm{~cm}^{-1}\left(\mathrm{CH}_{2}\right.$ wagging), $1180 \mathrm{~cm}^{-1}$ (C-C ring stretching), $1130 \mathrm{~cm}^{-1}$ (C-O-C glycosidic ether), $1074 \mathrm{~cm}^{-1}$ (C-O-C pyranose ring stretching), and $835 \mathrm{~cm}^{-1}$ (glycosidic linkages) [27,31-33]. The PAm hydrogel shows characteristic peaks at $3417 \mathrm{~cm}^{-1}$ and $3183 \mathrm{~cm}^{-1}$ related to the stretching vibration of amide functional group $\left(\mathrm{NH}_{2}\right)$ and $2925 \mathrm{~cm}^{-1}$ stretching vibrations $\mathrm{CH}_{2}$. Peaks at $1666 \mathrm{~cm}^{-1}$ and $1606 \mathrm{~cm}^{-1}$ are owing to the $\mathrm{C}=\mathrm{O}$ stretching and $\mathrm{NH}_{2}$ bending vibrations, respectively. Peaks at $1450 \mathrm{~cm}^{-1}, 1414 \mathrm{~cm}^{-1}$, and $1120 \mathrm{~cm}^{-1}$ are related to the $-\mathrm{CH}_{2}$ scissoring and $\mathrm{CN}$ and $\mathrm{N}-\mathrm{H}$ stretching vibrations, whereas the PAC3 hydrogel shows all the above characteristic peaks of the PAm, with slight shifts in their peaks (3403, 3177, 2916, 1664, 1613, 1453, 1419, and $1113 \mathrm{~cm}^{-1}$ ), which might be associated with the presence of CNC. This result indicates that CNC was 
well interacted with PAm through the formation of intermolecular bonds between the acrylamide and hydroxyl groups of CNC. During the formation, the hydroxyl groups of CNCs form a physical cross-linked structure with polyacrylamide chains, which leads to the formation of PAC hydrogel.
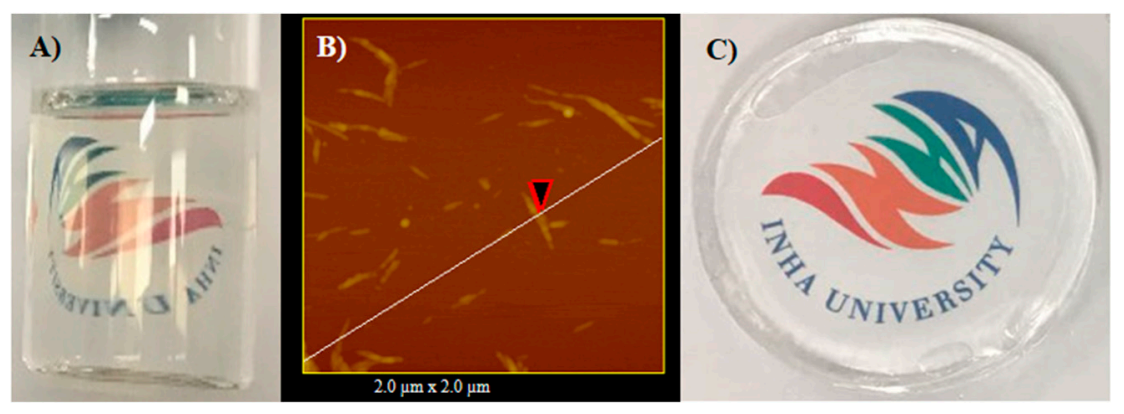

Figure 2. (A) Photograph of the prepared cellulose nanocrystal (CNC) suspension, (B) atomic force microscopy (AFM) image of the prepared CNCs, and (C) photograph of the prepared PAC hydrogel.

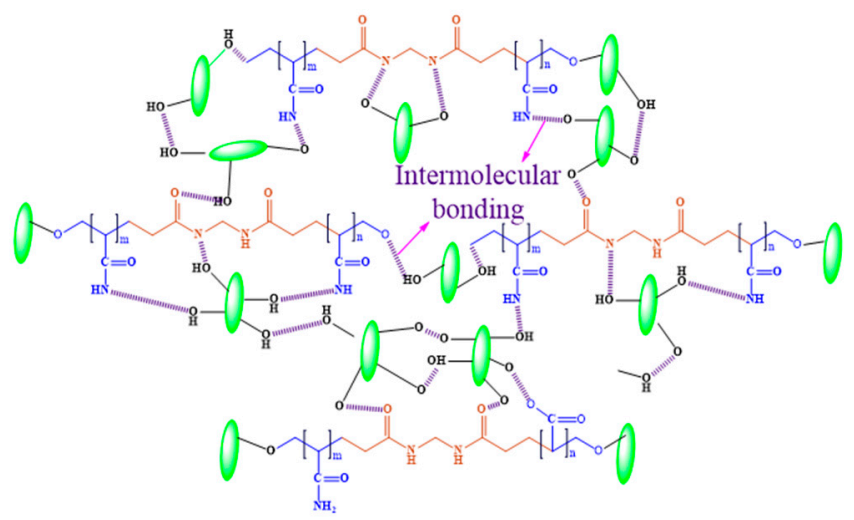

Figure 3. PAC hydrogel formation mechanism.

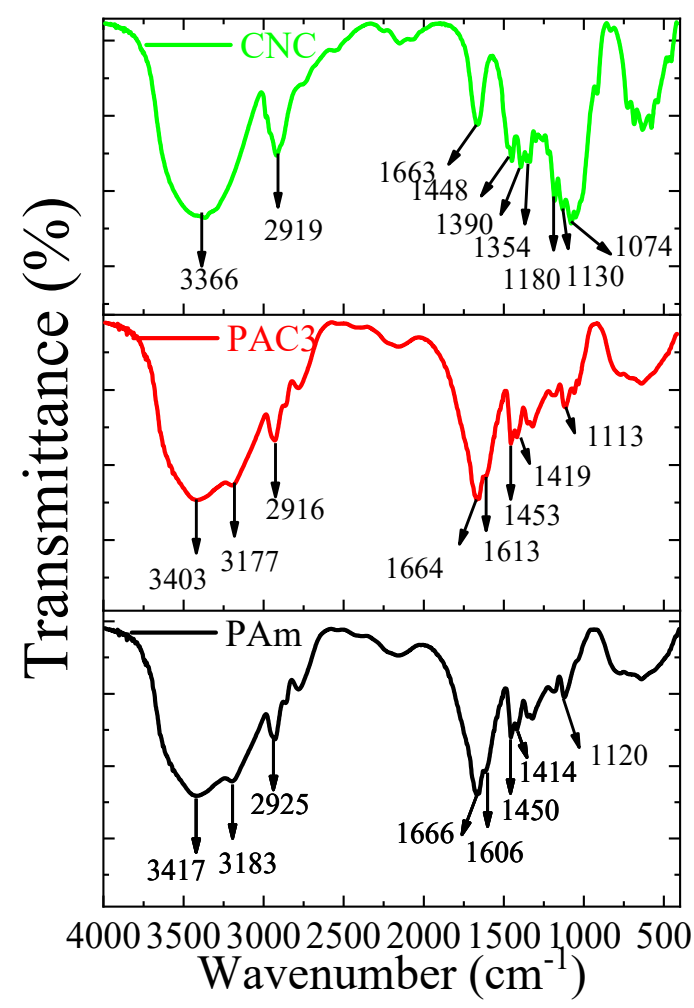

Figure 4. FTIR Spectra of PAm, CNC, and PAC3. 


\subsection{Physical Characteristics}

Figure 5 shows the XRD patterns of the CNC, Pam, and PAC3. It is an important analysis to understand the nature of the hydrogels developed. CNC displays four well-defined crystalline diffraction peaks at $2 \theta=14.6^{\circ}, 16.2^{\circ}, 22.58^{\circ}$, and $34.4^{\circ}$, respectively [20]. PAm hydrogel exhibits a broad diffraction peak at $2 \theta=23.2^{\circ}$, indicating an amorphous nature of the hydrogel. After blending $\mathrm{CNC}$ in polyacrylamide, PAC3 shows some crystalline characteristic peaks of $\mathrm{CNC}, 22.58^{\circ}$ and $16.2^{\circ}$ in an XRD pattern; meanwhile, the broad characteristic peak of PAm appears noticeably. This indicates that CNCs are dispersed in PAm without losing their crystalline characteristics. Recently, similar results were reported, and the intensity of the peak increased with the CNC content in CNC-based hybrid hydrogels [27].

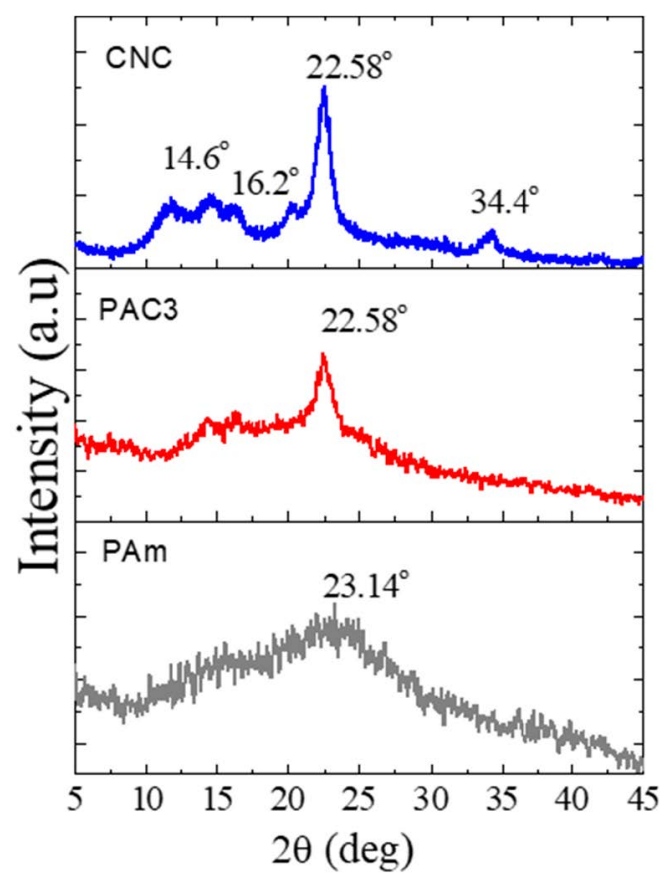

Figure 5. XRD spectra of PAm, CNC, and PAC3.

Figure 6 shows the DTA and TGA analysis results of the prepared hydrogels. DTA and TGA are useful techniques to characterize polymeric materials. The analysis results explain the glass transition $(\mathrm{Tg})$ temperature and thermal stability of the polymeric materials. In Figure $6 \mathrm{~A}$, the PAm hydrogels show endothermic peak at $169.6^{\circ} \mathrm{C}$, and this peak is slightly shifted by the addition of CNC $\left(\mathrm{PAC} 1=172.5^{\circ} \mathrm{C}\right)$. The endothermic peak further shifts up as the CNC content increases in the PAC hydrogels $\left(\mathrm{PAC} 3=174.8^{\circ} \mathrm{C}\right.$ ), which is associated with the formation of intermolecular bonds between two materials. Similarly, the thermal stability was also affected by the addition of $\mathrm{CNC}$ and the thermal stability as shown in Figure 6B. A $2 \%$ weight loss was observed in all the samples at below $100{ }^{\circ} \mathrm{C}$ due to the removal of absorbed water molecules, except CNC. In the prepared PAC hydrogels, three illustrious thermal degradation stages are shown within the following temperature ranges: $34-163{ }^{\circ} \mathrm{C}$ for the evaporation of water molecules, $163-338^{\circ} \mathrm{C}$ for the degradation of functional groups, and $338-451^{\circ} \mathrm{C}$ for the polymer backbone decomposition. Note that different weight residuals are observed at $500^{\circ} \mathrm{C}: 18.75,20.48,21.18$, and $22.01 \mathrm{wt}$ \% $\%$ for PAm, PAC1, PAC2, and PAC3, respectively. Overall, the TGA results indicate that PAm has lower thermal stability than PAC hydrogels, and the thermal stability of the PAC hydrogels increases along the CNC content.

The surface morphology of the hydrogels was confirmed by SEM. Figure 7 shows the SEM images of the prepared hydrogels. The SEM observation reveals that PAm exhibits a smooth surface area (Figure 7A), whereas PAC3 shows a rough surface area caused by the CNC distributed in the hydrogel 
matrix (Figure 7B). Furthermore, a cross-sectional SEM image of PAC3 clearly shows the presence of CNC in the polyacrylamide matrix (Figure 7C). This indicates that most of the CNCs are dispersed in the hydrogel matrix through intermolecular hydrogen bonds between polyacrylamide and CNCs. This result was confirmed by the previous FTIR and XRD studies. However, some aggregations of CNCs are shown. Note that above PAC3, high CNC concentration hydrogels are not easy to prepare because they do not have hydrogel formation, and severe aggregation of CNC occurs.
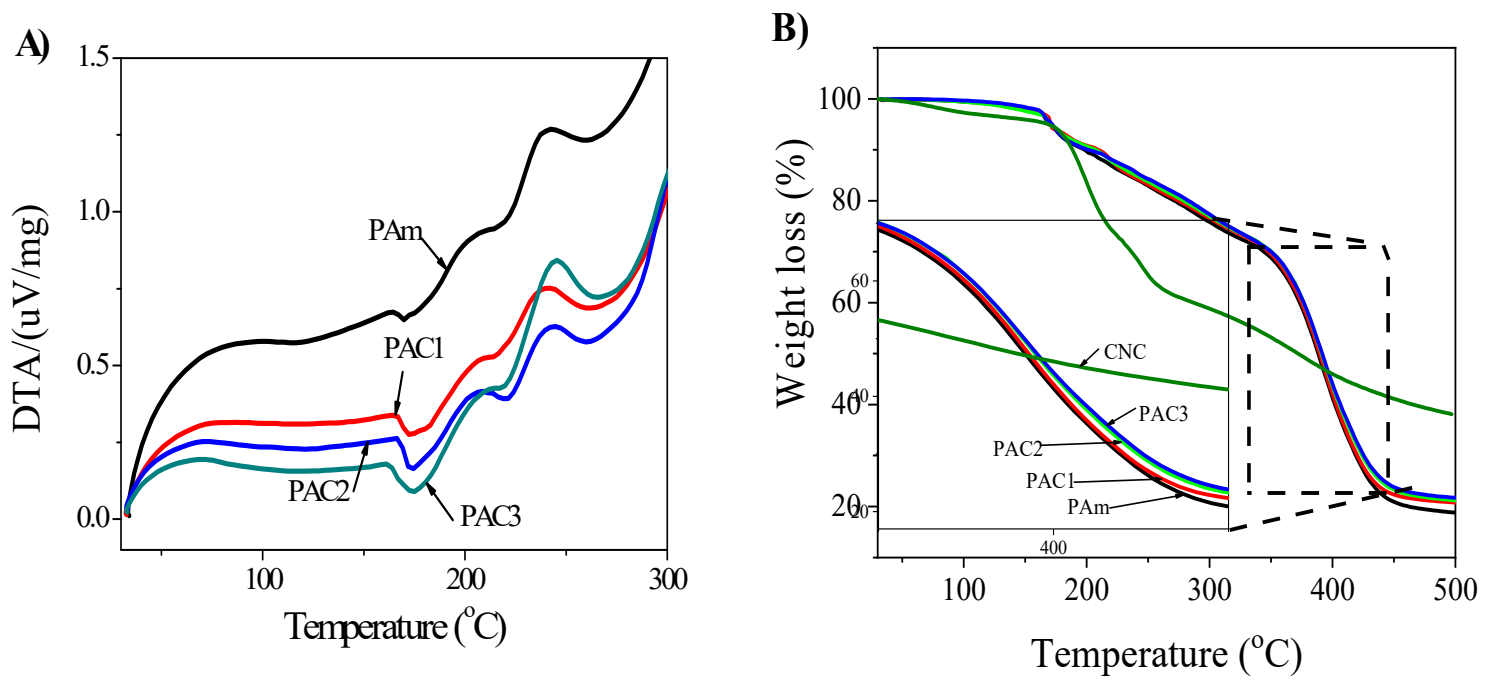

Figure 6. (A) Differential thermal analysis (DTA) analysis of PAm and PAC hydrogels; (B) TGA analysis of $\mathrm{CNC}$, Pam, and PAC hydrogels.
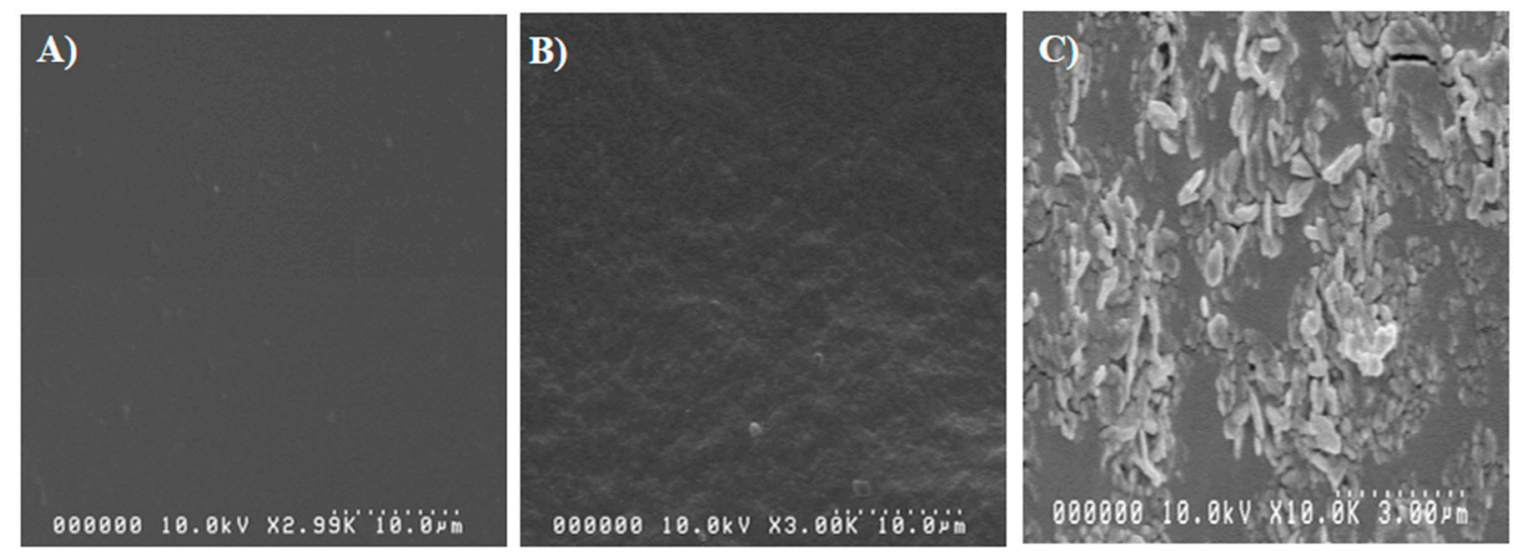

Figure 7. SEM images of (A) surface of PAm, (B) surface of PAC3, and (C) cross-section of PAC3.

\subsection{Swelling and Water Retention}

Swelling is one of the most important parameters in hydrogel technology. The effect of CNC concentration on the prepared hydrogels was studied via swelling and de-swelling tests. The swelling ratio was measured as a function of time and CNC content. Figure 8A shows the swelling ratios of the prepared hydrogels. The swelling ratios gradually increase with the swelling time at room temperature. Note that the CNC content affects the swelling ratios. For example, PAm shows $\mathrm{S}_{\mathrm{g} / \mathrm{g}}=11.69 \%$, which decreases in the case of PAC1 (10.87\%) and PAC2 (10.33\%). This might be due to the increase of physical cross-linking and reduced porosity in the hydrogels. However, PAC3 shows a higher swelling ratio than PAm, $\mathrm{S}_{\mathrm{g} / \mathrm{g}}=14.14 \%$, because of remnant CNCs that are shown in Figure $7 \mathrm{C}$ as aggregates. Beyond the swelling, the equilibrated hydrogels were removed from the DI water and de-swelled at room temperature for $24 \mathrm{~h}$, which is exactly the reverse of the swelling process, known as water retention. Figure $8 \mathrm{~B}$ shows the water retention of the prepared hydrogels. Water retention capacity gradually 
decreases with the time, depending on CNC content. PAm loses absorbed water quickly and evaporates approximately $90 \%$ of water content within $5.5 \mathrm{~h}$. Interestingly, the water retention capacity of PAC3 increases from 5.5 to $7.5 \mathrm{~h}$, owing to the hydrogen bonding formation between the water molecules and functional groups of the hydrogel matrix. The enhanced bonding formation delays the evaporation of the absorbed water molecules so as to improve water retention capacity. In a recent study, a similar phenomenon was reported in rice husk ash-based superabsorbent hydrogels [30]. Overall, the addition of CNC improved the swelling ratio and water retention capacity of PAC hydrogels.

The effect of $\mathrm{pH}$ on the swelling behavior of the prepared hydrogels was investigated at room temperature for $24 \mathrm{~h}$. Various $\mathrm{pH}$ solutions were prepared and adjusted using $0.1 \mathrm{M} \mathrm{HCl} / 0.1 \mathrm{M} \mathrm{NaOH}$ solutions with a pH meter (Orion Star A211 pH Benchtop Meter, Thermo Scientific, Beverly, MA, USA). The swelling ratio of the hydrogels at different $\mathrm{pH}$ values was calculated using Equation (1), and the results are shown in Figure $8 \mathrm{C}$. The swelling ratio is lower at below $\mathrm{pH}=2$, and increasing the $\mathrm{pH}$, the swelling ratio slightly increases up to $\mathrm{pH}=6$. When the $\mathrm{pH}$ increases from 8 to 12 , the swelling ratio drastically increases. In the literature, several studies explained the swelling ratio behavior at different $\mathrm{pH}$ levels $[30,31,33,34]$. Mostly, at lower $\mathrm{pH}$ levels, the $\mathrm{H}^{+}$ions are higher, and these ions form additional physical cross-linking with the functional groups of the hydrogel network. Owing to the formation of this physical cross-linking, the hydrogel network tends to shrink, and the swelling ratio decreases at lower $\mathrm{pH}$ levels. Further increasing the $\mathrm{pH}$ decreases the formation of the additional physical cross-linking so as to decrease the $\mathrm{H}^{+}$ions and increase the $\mathrm{OH}$ - ions with increasing the $\mathrm{pH}$. In general, $\mathrm{CNCs}$ have a large number of $-\mathrm{OH}$ groups in their structure [35]. It is noticeable that the swelling ratio increases at a high $\mathrm{pH}$, which is attributed to the repulsion of $\mathrm{pH}$ solution and the hydrogel network. Recently, a similar phenomenon was reported in the study of carclazyte-based carboxymethyl cellulose-g-poly (acrylic acid-co-acrylamide) superabsorbent hydrogels [36]. However, within the range of $\mathrm{pH} 6-8$, the swelling ratio is almost the same, which is attributed to the neutrality of the $\mathrm{pH}$ solutions.

The effect of temperature on the swelling ratio of the prepared hydrogels was investigated. The results are shown in Figure 8D. The prepared hydrogels were swollen at different temperatures from room temperature to $80^{\circ} \mathrm{C}$, and the swelling ratio was calculated when the time was $1400 \mathrm{~min}$. Increasing the temperature, the swelling ratio was consequently enhanced. Generally, hydrogels swell in water through the expansion of their chain networks due to the interaction between the polymeric chain networks and water molecules, which occurs through the entanglement of the interpenetrated (such as capillary, osmotic, and hydration forces) polymeric hydrogel network. When the temperature increases, the interaction behavior disturbs the disentanglement of interpenetrated polymeric chains and destruction of hydrogen bonding between polymer molecules occurs. Thus, the swelling ratio increases [37].

Based on the $\mathrm{pH}$ swelling study and temperature effect on the swelling ratio, the effect of temperature on the $\mathrm{pH}$ swelling ratio was studied at lower and higher $\mathrm{pH}$ values at different temperatures. Figure $9 \mathrm{~A}, \mathrm{~B}$ shows the temperature effect on $\mathrm{pH}=2$ and $\mathrm{pH}=12$ swelling ratios. In both $\mathrm{pH}$ values, the swelling ratio increases with the temperature increase: When the temperature changes from 30 to $80^{\circ} \mathrm{C}$, the swelling ratio of PAC3 increases from 13.2 to 16.3 for $\mathrm{pH}=2$ and $46.3 \mathrm{~g}$ to 161.7 for $\mathrm{pH}=12$, respectively. As anticipated, PAm hydrogel shows a smaller swelling ratio than PAC3. Figure $9 \mathrm{C}$ shows the different $\mathrm{pH}$ swelling ratio values at $80^{\circ} \mathrm{C}$. Similarly, the values increase with increasing the $\mathrm{pH}$ level. Overall, $\mathrm{PAC} 3$ shows a 4 times higher swelling ratio at $\mathrm{pH}=12$ than $\mathrm{pH}=2$. Note that $\mathrm{pH}$ and temperature affect the swelling ratio simultaneously. For better understanding, digital images of the dried hydrogel, room temperature, and $80^{\circ} \mathrm{C}$ swollen hydrogel at $\mathrm{pH}=12$ are shown in Figure 9D. 

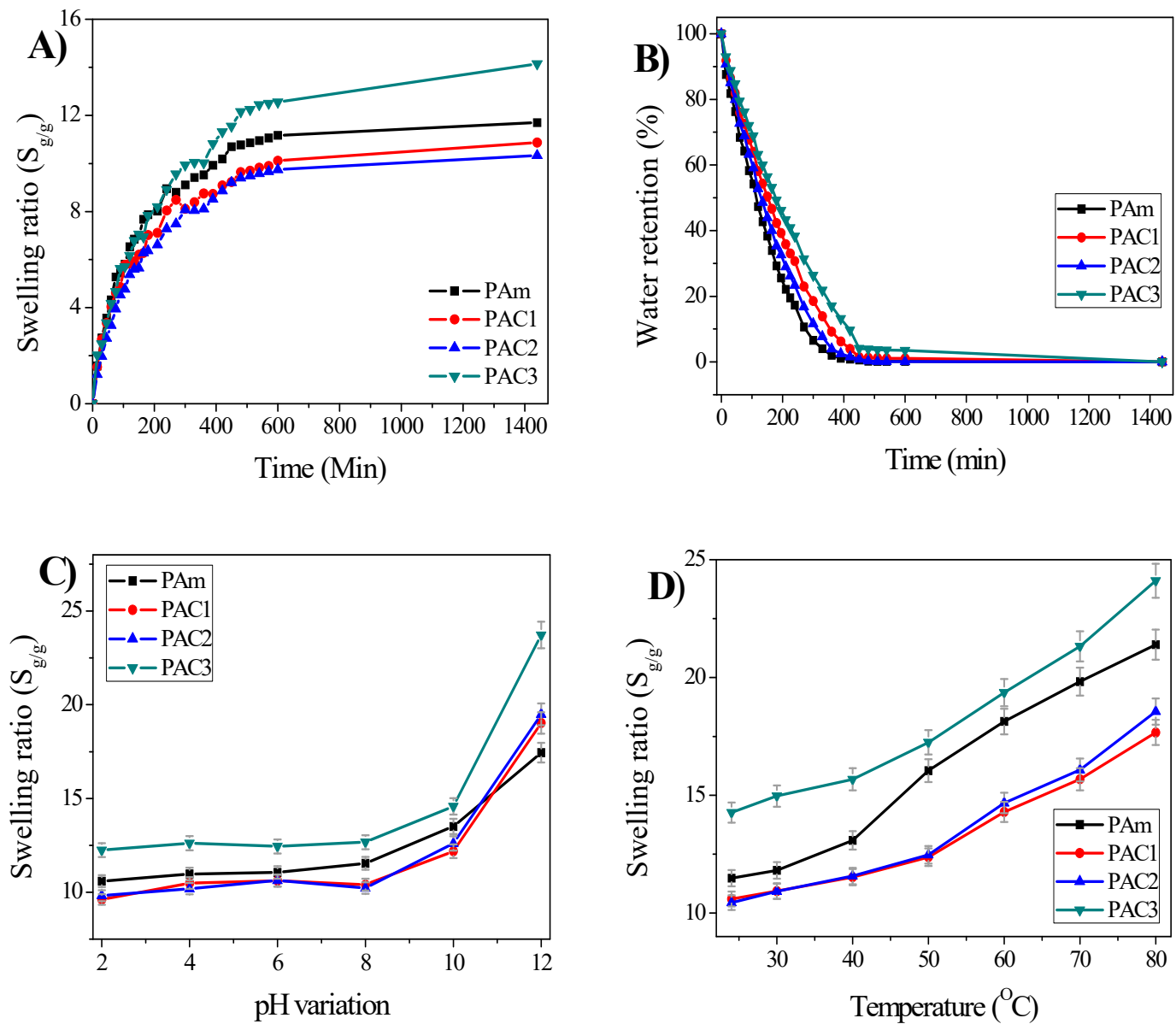

Figure 8. (A) Swelling ratio studies in de-ionized (DI) water, (B) water retention studies of PAm and PAC hydrogels, (C) swelling ratio at different $\mathrm{pHs}(2-12)$, and (D) temperature effect of swelling ratio in DI water.
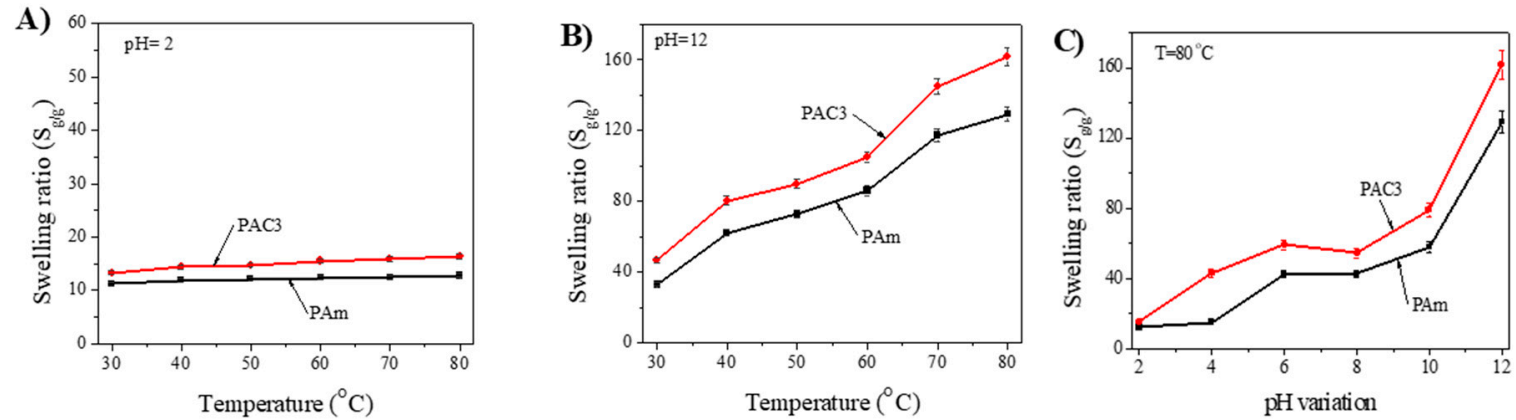

D)

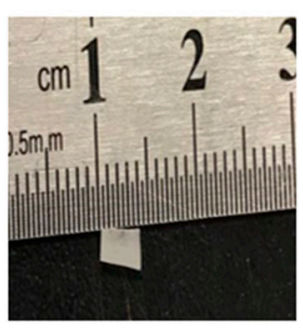

pH 12
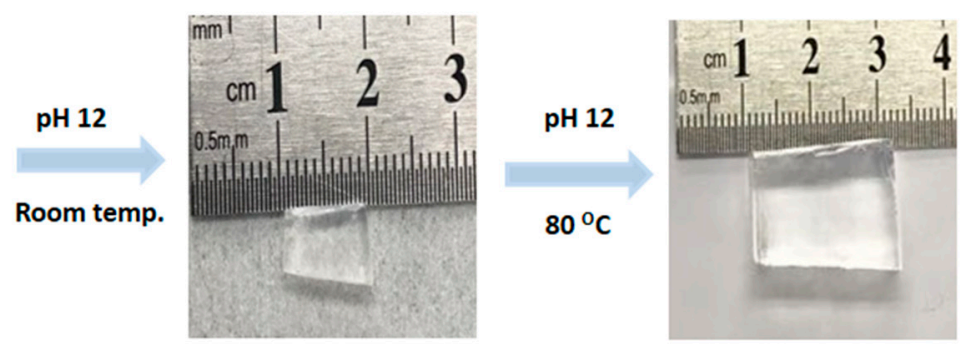

Figure 9. Swelling ratio studies (A), $\mathrm{pH} 2(\mathbf{B}) \mathrm{pH} 12$ at various temperatures, (C) swelling ratio at $80{ }^{\circ} \mathrm{C}$ in different $\mathrm{pH}$ solutions, and (D) digital images of swollen hydrogels in $\mathrm{pH} 12$ room temperature and $80^{\circ} \mathrm{C}$. 


\subsection{Swelling Kinetics}

The swelling property plays an important role in hydrogel technology, and various techniques are available to study their swelling kinetics mechanism in the literature [38-41]. Among them, a simple kinetic analysis equation is used in a second order equation:

$$
\frac{d s}{d t}=k_{s}\left(S_{e q}-S\right)^{2}
$$

where $d s / d t, k_{s}, S_{e q}$, and $S$ refer to the rehydration ratio, swelling rate constant, equilibrium swelling, and swelling ratio at $t$, respectively. After definite integration by applying the initial condition such as $S=0$ at $t=0$ and $S=S_{e q}$, Equation (3) converts to:

$$
\frac{t}{S}=A+B t
$$

where $A=1 / k_{s} S_{e q}{ }^{2}$ is the initial swelling rate of the hydrogel composite and $k_{s}$ is the swelling rate constant, and $B\left(=1 / S_{e q}\right)$ is the converse of the maximum or equilibrium swelling. In order to investigate the above kinetic model for the PAC hydrogels, the graph was drawn $t / s$ versus $t$ in Figure $10 \mathrm{~A}$, and the slopes and intersections of plotted lines give the initial rate of swelling $\left(r_{i}\right)$, the swelling rate constant $\left(k_{s}\right)$, and the theoretical equilibrium $\left(S_{e q}\right)$ values, shown in Table 2 . According to the results, the theoretical swelling ratio is close to the experimental swelling ratios. The swelling mechanism of the hydrogels can be determined using the below equation:

$$
\text { swelling ratio }(S)=\left(\frac{W_{s}-W_{d}}{W_{d}}\right)=k t^{n}
$$

where $S, W_{s}$, and $W_{d}$ are the fraction swelling ratio at time $t$, the weight of the swollen hydrogels at time $t$, and the weight of the dried hydrogels at time $t=0$, respectively, $k$ is the swelling constant and $n$ is the swelling exponent, which indicates the water transport mechanism [42,43]. The above equation was used to estimate the $n$ value using up to $60 \%$ of the swelling ratio values, then the plot was drawn between the $\ln S$ versus $\ln t$ and slope of the obtain straight lines gives the swelling exponent value $n$. Based on the $n$ values, the diffusion mechanism is identified. When $n \leq 0.5$, the diffusion mechanism is a Fickian diffusion, and when $0.5<n<1.0$, it indicates non-Fickian diffusion or anomalous diffusion. In anomalous diffusion, the diffusion and relaxation are said to be isochronally effective. If the $n$ value is exactly equal to 1 , the diffusion mechanism is designated as Case II diffusion, and when the $n$ value is above $1(n>1)$ it is called a super Case II diffusion mechanism, which is very rarely possible [44]. Figure 10B shows the slope and intercept of the straight lines that can give $n$ and $k$ values, shown in Table 2. The developed hydrogels show a Fickian type diffusion mechanism, which is more suitable for biomedical applications, especially in controlled drug delivery applications. The swelling constant $k$ can be described with diffusion coefficient $D$ for a Fickian diffusion. As $n$ is approximately taken as 0.5 for an ideal Fickian diffusion, the swelling ratio of the hydrogels can be written using the equation:

$$
S=\sqrt{\frac{D}{\pi r^{2}}} \sqrt{t}
$$

where $D, r, S$, and $t$ represent the diffusion coefficient of the hydrogel, the radius of the hydrogel, swelling ratio, and time, respectively. $\sqrt{D t}$ represents a diffusion length. The diffusion coefficient value $D$ was calculated by drawing the plot $S$ versus $t^{1 / 2}$ (Figure 10C), and the slope of the line gives the diffusion coefficient value $D$. The diffusion coefficient value of PAm hydrogel is $0.4577 \mathrm{~cm}^{2} \cdot \mathrm{s}^{-1}$, while the case of PAC3 is $0.5377 \mathrm{~cm}^{2} \cdot \mathrm{s}^{-1}$, which indicates a faster diffusion rate of molecules in PAC3 than PAm. A large diffusion coefficient is directly associated with the swelling ratio. The higher water diffusion might be associated with the presence of CNC in the hydrogel network. Further, as the 
CNC concentration increased, the water retention capacity of the prepared hydrogels was improved. The kinetic parameters obtained are shown in Table 2.

Hydrogels that can produce large swelling with $\mathrm{pH}$ and temperature are attractive for biomedical applications such as drug delivery, active wound healing, and adaptive scafolds for artificial organs. Softness and shape change behaviors are advantages of these materials. However, biocompatibility, mitigation of toxicity, and reliability are challenges that should be overcome.
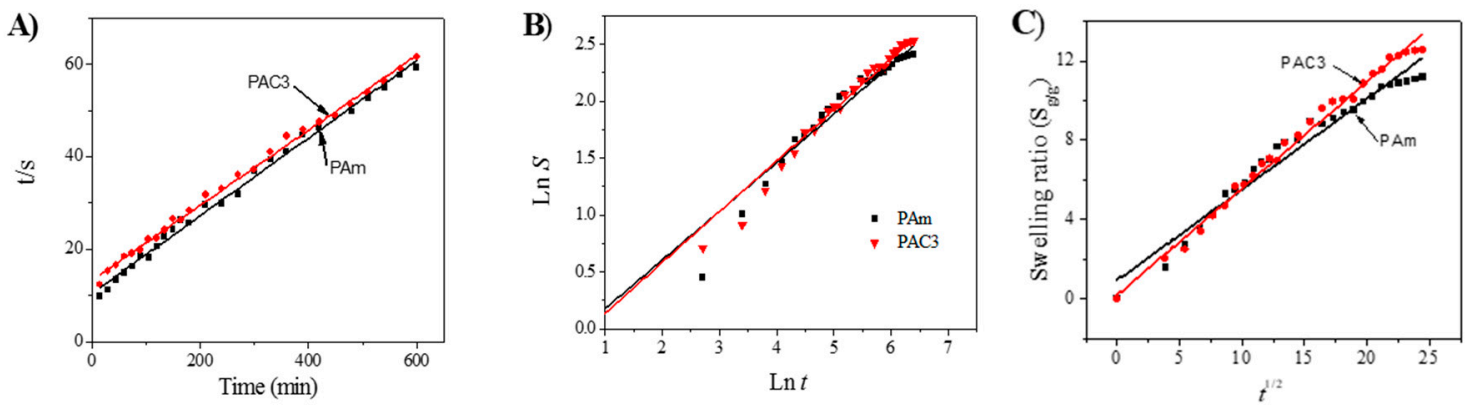

Figure 10. Swelling kinetics curves of PAm and PAC3 in DI water: (A) $t / s$ verses $t$ curves, (B) $\operatorname{Ln} S$ verses $\operatorname{Ln} t$, and $(\mathbf{C})$ swelling ratio verses $t^{1 / 2}$ curves.

Table 2. Swelling kinetics parameters of PAC hydrogels.

\begin{tabular}{|c|c|c|c|c|c|}
\hline $\begin{array}{l}\text { Hydrogel } \\
\text { Code }\end{array}$ & $\begin{array}{l}\text { Swelling } \\
\text { Exponent } \\
\quad(n)\end{array}$ & $\begin{array}{l}\text { Diffusion } \\
\text { Coefficient } \\
\text { (D) } \mathrm{cm}^{2} \cdot \mathrm{s}^{-1}\end{array}$ & $\begin{array}{c}\text { Initial Swelling } \\
\text { Rate }\left(r_{i}\right) \\
\text { [g water/g } \\
\text { hydrogel]/min }\end{array}$ & $\begin{array}{c}\text { Theoretical } \\
\text { Equilibrium Swelling } \\
\left(S_{e q}\right) \text { [g Water/g } \\
\text { Hydrogel] }\end{array}$ & $\begin{array}{c}\text { Swelling Rate } \\
\text { Constant }\left(k_{s}\right) \\
\text { [g Hydrogel/g } \\
\text { Water/min] }\end{array}$ \\
\hline PAm & 0.4279 & 0.4577 & 0.0744 & 10.53 & 8.9158 \\
\hline PAC3 & 0.4473 & 0.5377 & 0.0619 & 13.184 & 14.1123 \\
\hline
\end{tabular}

\section{Conclusions}

The PAC hydrogels were prepared via a radical polymerization in an aqueous solution of CNCs using monomers, cross-linkers, and initiators. CNC acted as a nanofiller through the formation of intermolecular interaction. The formation of intermolecular bonds between the acrylamide and hydroxyl groups of CNC in the prepared hydrogels were confirmed by FTIR and XRD studies. DTA analysis results explained the endothermic peak increase as CNC content increased. Similarly, the thermal stability was improved by the addition of CNCs in the synthesized hydrogels, and SEM studies revealed the CNCs well dispersed in the hydrogels.

The swelling ratio gradually increased with time at room temperature, and the $\mathrm{CNC}$ content affected the swelling ratio. The PAC hydrogels showed excellent swelling behaviors in terms of $\mathrm{pH}$, temperature, and temperature with $\mathrm{pH}$. Increasing the $\mathrm{pH}$ with temperature, the PAC3 hydrogel exhibited a 6 times higher swelling ratio than the initial condition. A swelling kinetics study explained that the diffusion mechanism of PAC hydrogels is a Fickian diffusion mechanism. The resulting PAC hydrogels are interesting as potential biomaterials due to their good swelling ( $\mathrm{pH}$ and temperature) and can be used in the field of biomedical implants, especially in controlled drug delivery applications.

Author Contributions: Conceptualization, T.J. and J.K.; Methodology, T.J. and H.-U.K.; Validation, J.W.K.; Formal Analysis, T.J.; Investigation, T.J., H.C.K., and J.W.K.; Resources, H.C.K.; Data Curation, T.J.; Writing-Original Draft Preparation, T.J.; Writing-Review and Editing, J.K.; Visualization, T.J. and H.C.K.; Supervision, J.K.; Project Administration, J.W.K.; Funding Acquisition, J.K.

Funding: This research was supported by Creative Research Initiatives Program through the National Research Foundation of Korea (NRF) funded by the Ministry of Science, Technology and ICT (NRF-2015R1A3A2066301).

Conflicts of Interest: The authors declare no conflicts of interest. 


\section{References}

1. Jayaramudu, T.; Ko, H.-U.; Kim, H.C.; Kim, J.W.; Li, Y.; Kim, J. Transparent and semi-interpenetrating network $\mathrm{P}$ (vinyl alcohol)-P(Acrylic acid) hydrogels: $\mathrm{pH}$ responsive and electroactive application. Int. J. Smart Nano Mater. 2017, 8, 80-94. [CrossRef]

2. Jayaramudu, T.; Raghavendra, G.M.; Varaprasad, K.; Sadiku, R.; Raju, K.M. Development of novel biodegradable Au nanocomposite hydrogels based on wheat: For inactivation of bacteria. Carbohydr. Polym. 2013, 92, 2193-2200. [CrossRef] [PubMed]

3. Rasoulzadeh, M.; Namazi, H. Carboxymethyl cellulose/graphene oxide bio-nanocomposite hydrogel beads as anticancer drug carrier agent. Carbohydr. Polym. 2017, 168, 320-326. [CrossRef] [PubMed]

4. Van Nieuwenhove, I.; Salamon, A.; Adam, S.; Dubruel, P.; Van Vlierberghe, S.; Peters, K. Gelatin- and starch-based hydrogels. Part B: In vitro mesenchymal stem cell behavior on the hydrogels. Carbohydr. Polym. 2017, 161, 295-305. [CrossRef] [PubMed]

5. Varaprasad, K.; Raghavendra, G.M.; Jayaramudu, T.; Yallapu, M.M.; Sadiku, R. A mini review on hydrogels classification and recent developments in miscellaneous applications. Mater. Sci. Eng. C 2017, 79, $958-971$. [CrossRef] [PubMed]

6. Jayaramudu, T.; Li, Y.; Ko, H.-U.; Shishir, I.R.; Kim, J. Poly(acrylic acid)-Poly(vinyl alcohol) hydrogels for reconfigurable lens actuators. Int. J. Precis. Eng. Manuf. Technol. 2016, 3, 375-379. [CrossRef]

7. Jayaramudu, T.; Raghavendra, G.M.; Varaprasad, K.; Raju, K.M.; Sadiku, E.R.; Kim, J. 5-Fluorouracil encapsulated magnetic nanohydrogels for drug-delivery applications. J. Appl. Polym. Sci. 2016, 133, 1-10. [CrossRef]

8. Varaprasad, K.; Jayaramudu, T.; Sadiku, E.R. Removal of dye by carboxymethyl cellulose, acrylamide and graphene oxide via a free radical polymerization process. Carbohydr. Polym. 2017, 164, 186-194. [CrossRef] [PubMed]

9. Wang, L.Y.; Wang, M.J. Removal of Heavy Metal Ions by Poly(vinyl alcohol) and Carboxymethyl Cellulose Composite Hydrogels Prepared by a Freeze-Thaw Method. ACS Sustain. Chem. Eng. 2016, 4, $2830-2837$. [CrossRef]

10. Jayaramudu, T.; Raghavendra, G.M.; Varaprasad, K.; Sadiku, R.; Ramam, K.; Raju, K.M. Iota-Carrageenanbased biodegradable Ag0 nanocomposite hydrogels for the inactivation of bacteria. Carbohydr. Polym. 2013, 95, 188-194. [CrossRef]

11. Ahmed, E.M. Hydrogel: Preparation, characterization, and applications: A review. J. Adv. Res. 2015, 6, 105-121. [CrossRef] [PubMed]

12. Sojka, R.E.; Bjorneberg, D.L.; Entry, J.A.; Lentz, R.D.; Orts, W.J. Polyacrylamide in Agriculture and Environmental Land Management. Adv. Agron. 2007, 92, 75-162.

13. Kai, D.; Prabhakaran, M.P.; Stahl, B.; Eblenkamp, M.; Wintermantel, E.; Ramakrishna, S. Mechanical properties and in vitro behavior of nanofiber-hydrogel composites for tissue engineering applications. Nanotechnology 2012, 23, 095705. [CrossRef] [PubMed]

14. Guo, Y.G.; Hu, J.-S.; Liang, H.-P.; Wan, L.-J.; Bai, C.-L. Highly Dispersed Metal Nanoparticles in Porous Anodic Alumina Films Prepared by a Breathing Process of Polyacrylamide Hydrogel. Chem. Mater. 2003, 15, 4332-4336. [CrossRef]

15. Dai, T.; Qing, X.; Wang, J.; Shen, C.; Lu, Y. Interfacial polymerization to high-quality polyacrylamide/ polyaniline composite hydrogels. Compos. Sci. Technol. 2010, 70, 498-503. [CrossRef]

16. Guan, T.; Ceyssens, F.; Puers, R. Fabrication and testing of a MEMS platform for characterization of stimuli-sensitive hydrogels. J. Micromech. Microeng. 2012, 22, 087001. [CrossRef]

17. Kim, H.C.; Gao, X.; Jayaramudu, T.; Kang, J.; Kim, J. Optical and Electro-Active Properties of Polyacrylamide /CNC Composite Hydrogels. J. Korean Soc. Precis. Eng. 2017, 34, 575-580. [CrossRef]

18. Roy, D.; Semsarilar, M.; Guthrie, J.T.; Perrier, S. Cellulose modification by polymer grafting: A review. Chem. Soc. Rev. 2009, 38, 2046. [CrossRef]

19. Gao, X.; Sadasivuni, K.K.; Kim, H.-C.; Min, S.-K.; Kim, J. Designing pH-responsive and dielectric hydrogels from cellulose nanocrystals. J. Chem. Sci. 2015, 127, 1119-1125. [CrossRef]

20. Sadasivuni, K.K.; Kafy, A.; Zhai, L.; Ko, H.U.; Mun, S.; Kim, J. Transparent and flexible cellulose nanocrystal/reduced graphene oxide film for proximity sensing. Small 2015, 11, 994-1002. [CrossRef] 
21. Sadasivuni, K.K.; Ponnamma, D.; Ko, H.-U.; Kim, H.C.; Zhai, L.; Kim, J. Flexible $\mathrm{NO}_{2}$ sensors from renewable cellulose nanocrystals/iron oxide composites. Sens. Actuators B Chem. 2016, 233, 633-638. [CrossRef]

22. Kim, J.-H.; Shim, B.S.; Kim, H.S.; Lee, Y.-J.; Min, S.-K.; Jang, D.; Abas, Z.; Kim, J. Review of nanocellulose for sustainable future materials. Int. J. Precis. Eng. Manuf. Technol. 2015, 2, 197-213. [CrossRef]

23. Ooi, S.Y.; Ahmad, I.; Amin, M.C.I.M. Cellulose nanocrystals extracted from rice husks as a reinforcing material in gelatin hydrogels for use in controlled drug delivery systems. Ind. Crops Prod. 2016, 93, 227-234. [CrossRef]

24. Yang, J.; Han, C.-R.; Duan, J.-F.; Ma, M.-G.; Zhang, X.-M.; Xu, F.; Sun, R.-C.; Xie, X.-M. Studies on the properties and formation mechanism of flexible nanocomposite hydrogels from cellulose nanocrystals and poly(acrylic acid). J. Mater. Chem. 2012, 22, 22467-22480. [CrossRef]

25. Yuan, N.; Xu, L.; Zhang, L.; Ye, H.; Zhao, J.; Liu, Z.; Rong, J. Superior hybrid hydrogels of polyacrylamide enhanced by bacterial cellulose nanofiber clusters. Mater. Sci. Eng. C 2016, 67, 221-230. [CrossRef]

26. Mohammed, N.; Grishkewich, N.; Waeijen, H.A.; Berry, R.M.; Tam, K.C. Continuous flow adsorption of methylene blue by cellulose nanocrystal-alginate hydrogel beads in fixed bed columns. Carbohydr. Polym. 2016, 136, 1194-1202. [CrossRef]

27. Kumar, A.; Rao, K.M.; Han, S.S. Synthesis of mechanically stiff and bioactive hybrid hydrogels for bone tissue engineering applications. Chem. Eng. J. 2017, 317, 119-131. [CrossRef]

28. Jayaramudu, T.; Ko, H.-U.; Kim, H.; Kim, J.J.; Muthoka, R.; Kim, J.J. Electroactive Hydrogels Made with Polyvinyl Alcohol/Cellulose Nanocrystals. Materials 2018, 11, 1615. [CrossRef]

29. Zhou, C.; Wu, Q.; Yue, Y.; Zhang, Q. Application of rod-shaped cellulose nanocrystals in polyacrylamide hydrogels. J. Colloid Interface Sci. 2011, 353, 116-123. [CrossRef]

30. Gharekhani, H.; Olad, A.; Mirmohseni, A.; Bybordi, A. Superabsorbent hydrogel made of NaAlg-g-poly(AAco-AAm) and rice husk ash: Synthesis, characterization, and swelling kinetic studies. Carbohydr. Polym. 2017, 168, 1-13. [CrossRef]

31. Jayaramudu, T.; Ko, H.-U.; Zhai, L.; Li, Y.; Kim, J. Preparation and characterization of hydrogels from polyvinyl alcohol and cellulose and their electroactive behavior. Soft Mater. 2017, 15, 64-72. [CrossRef]

32. Sadasivuni, K.K.; Ponnamma, D.; Ko, H.-U.; Zhai, L.; Kim, H.-C.; Kim, J. Electroactive and Optically Adaptive Bionanocomposite for Reconfigurable Microlens. J. Phys. Chem. B 2016, 120, 4699-4705. [CrossRef] [PubMed]

33. George, J.; Sabapathi, S.N. Cellulose nanocrystals: Synthesis, functional properties, and applications. Nanotechnol. Sci. Appl. 2015, 8, 45-54. [CrossRef] [PubMed]

34. Yun, J.; Kim, H. Preparation of poly(vinyl alcohol)/poly(acrylic acid) microcapsules and microspheres and their pH-responsive release behavior. J. Ind. Eng. Chem. 2009, 15, 902-906. [CrossRef]

35. Rao, K.M.; Kumar, A.; Han, S.S. Polysaccharide based bionanocomposite hydrogels reinforced with cellulose nanocrystals: Drug release and biocompatibility analyses. Int. J. Biol. Macromol. 2017, 101, 165-171.

36. Dai, H.; Huang, H. Enhanced Swelling and Responsive Properties of Pineapple Peel Carboxymethyl Cellulose-g-poly(acrylic acid-co-acrylamide) Superabsorbent Hydrogel by the Introduction of Carclazyte. J. Agric. Food Chem. 2017, 65, 565-574. [CrossRef] [PubMed]

37. Kong, L.; Gao, Y.; Cao, W.; Gong, Y.; Zhao, N.; Zhang, X. Preparation and characterization of nano-hydroxyapatite/chitosan composite scaffolds. J. Biomed. Mater. Res. A 2005, 75, 275-282. [CrossRef] [PubMed]

38. Wang, C.; Li, Y.; Hu, Z. Swelling Kinetics of Polymer Gels. Macromolecules 1997, 30, 4727-4732. [CrossRef]

39. Plunkett, K.N.; Kraft, M.L.; Yu, Q.; Moore, J.S. Swelling Kinetics of Disulfide Cross-Linked Microgels. Macromolecules 2003, 36, 3960-3966. [CrossRef]

40. Zhao, Z.X.X.; Li, Z.; Xia, Q.B.B.; Bajalis, E.; Xi, H.X.X.; Lin, Y.S.S. Swelling/deswelling kinetics of PNIPAAm hydrogels synthesized by microwave irradiation. Chem. Eng. J. 2008, 142, 263-270. [CrossRef]

41. Grassi, G.; Farra, R.; Caliceti, P.; Guarnieri, G.; Salmaso, S.; Carenza, M.; Grassi, M. Temperature-Sensitive Hydrogels. Am. J. Drug Deliv. 2005, 3, 239-251. [CrossRef]

42. Peniche, C.; Argüelles-Monal, W.; Davidenko, N.; Sastre, R.; Gallardo, A.; San Román, J. Self-curing membranes of chitosan/PAA IPNs obtained by radical polymerization: Preparation, characterization and interpolymer complexation. Biomaterials 1999, 20, 1869-1878. [CrossRef] 
43. Yiamsawas, D.; Kangwansupamonkon, W.; Chailapakul, O.; Kiatkamjornwong, S. Synthesis and swelling properties of poly[acrylamide-co-(crotonic acid)] superabsorbents. React. Funct. Polym. 2007, 67, 865-882. [CrossRef]

44. Bajpai, A.K.; Shrivastava, M. Swelling Kinetics of a Hydrogel of Poly(ethylene glycol) and Poly(acrylamide-co-styrene). J. Appl. Polym. Sci. 2002, 85, 1419-1428. [CrossRef]

(C) 2019 by the authors. Licensee MDPI, Basel, Switzerland. This article is an open access article distributed under the terms and conditions of the Creative Commons Attribution (CC BY) license (http://creativecommons.org/licenses/by/4.0/). 